\title{
Assessment of Post-COVID-19 Quality of Life Using the Quality of Life Index
}

\section{Maaidah M Algamdi (D)}

Department of Nursing, Faculty of Applied Medical Sciences, University of Tabuk, Tabuk, Saudi Arabia
Correspondence: Maaidah M Algamdi Department of Nursing, Faculty of Applied Medical Sciences, University of Tabuk, Tabuk, Saudi Arabia Tel +966560091866

Email ialghamdi@ut.edu.sa
Background: COVID-19 has impacted many aspects of peoples' quality of life (QOL).

Aim: To assess the QOL of post-COVID-19 cases and determine their associated sociodemographic attributes.

Methods: A cross-sectional community-based study targeted recovered COVID-19 cases using an online questionnaire. An Arabic version of the Quality of Life Index (QLI) was evaluated for reliability and validity using Cronbach's alpha and Spearman's product moment tests, respectively. Descriptive analysis, Mann-Whitney U, Kruskal-Wallis H, and Spearman correlation tests were used to investigate the relationships between QOL and study independent variables, including sociodemographic characteristics, time since infection, intention for vaccination, perception of the influence of COVID-19 on general health, history of hospitalization, and history of chronic illness. Subgroups were compared using a Student's $t$-test for normally distributed data and the Wilcoxon rank-sum test or the Kruskal-Wallis test for non-normally distributed data.

Results: In a sample of 449 respondents, the total QLI score was $22.64 \pm 4.36$; for subscales, it ranged from $20.86 \pm 5.04$ to $24.99 \pm 4.74$. Males had significantly higher health and functioning subscale (HFSUB) scores compared to females $(p=0.033)$. Employed cases had significantly higher social and economic subscale (SOCSUB) scores than unemployed cases $(p=0.000)$. Married people reported significantly higher family subscale (FAMSUB) scores $(p=0.000)$ than unmarried people. People who believe that their general health was affected by COVID-19 had significantly lower HFSUB and psychological and spiritual subscale (PSPSUB) scores $(\mathrm{p}=0.000$ and $\mathrm{p}=0.021$, respectively). Individuals with a history of hospital admissions scored lower on PSPSUB $(\mathrm{p}=0.000)$. Age was significantly associated with both SOCSUB $(p=0.006)$ and FAMSUB $(p=0.040)$.

Conclusion: Sociodemographic attributes of people with a history of COVID-19 revealed significant differences in some QOL domains, as measured by the Arabic version of the generic QLI. History of hospitalization and beliefs about COVID-19's impact on general health negatively influenced individual's HFSUB and PSPSUB.

Keywords: quality of life, COVID-19, post-COVID-19 cases, Saudi Arabia, quality of life index

\section{Introduction}

In late 2019, a novel coronavirus started spreading from Wuhan, China, to the entire globe. ${ }^{1}$ The World Health Organization officially named the disease caused by this virus Coronavirus Disease 2019 (COVID-19). ${ }^{2}$ Currently, the world is still struggling with the spread of COVID-19. The numbers of cases and deaths are increasing every day (available at https://covid19.who.int/). The virus has increased the burden on health professionals and health care systems in many countries. ${ }^{3-6}$ In 
Saudi Arabia, the first case of COVID-19 was confirmed in March 2020. The number of cases continued to rise until a significant decrease occurred at the end of 2020, but then, an increase began again in April 2021 (data available at https://covid19.moh.gov.sa/). However, the total number of COVID-19 cases in Saudi Arabia has remained relatively low due to prompt precautionary action taken by the government. $^{7}$ As a lockdown started at the end of March 2020, it was predicted that confirmed cases would be reduced by 400,000 by the end of September $2020 .^{8}$ Ultimately, the number of cases was successfully decreased due to the lockdown and precautionary measures implemented during the mentioned period.

Exploration into the impact of the COVID-19 pandemic on the quality of life (QOL) for the general populations of Saudi Arabia, Lebanon, Italy, the United Kingdom, the United States, Morocco, and China has shown substantial influences, especially regarding physical, psychological, social, and spiritual health. ${ }^{9-18}$ The QOL of health care professionals was also impacted by COVID-19. ${ }^{19,20}$ Many studies have reported that various symptoms are experienced during and after COVID-19 infection. $^{21-24}$ Other studies have shown that postCOVID-19 symptoms are minimal for about 1-6 months after diagnosis, except for people with comorbidities. ${ }^{25,26}$ During the pandemic, families have encountered many issues that have influenced their well-being, such as violence, conflict, and divorce. ${ }^{27,28}$ Economists have also witnessed deterioration as a consequence of the lockdowns and quarantines. ${ }^{29,30}$ COVID-19 patients have experienced mental health issues, such as depression. ${ }^{9}$ Additionally, poor QOL has been reported after one month for discharged COVID-19 patients, especially concerning physical and psychological aspects of well-being. ${ }^{31,32}$ After three months, their QOL has been reported to still be significantly lower than the normal population. ${ }^{33}$ Moreover, in terms of care, non-hospitalized COVID-19 patients have been reported to either be self-dependent (independent) or care-dependent (depend on others). ${ }^{34,35}$ QOL has been explored for non-hospitalized patients, showing no difference from the normal population. However, no large impact was found in the mental health domain. $^{36}$

QOL is defined as an individual's feelings of wellbeing in terms of satisfaction with important aspects of life. ${ }^{37}$ Individual preferences in defining their goals, choices, and expectations in life will help determine their QOL. ${ }^{38}$ Many studies have explored the QOL of recovered
COVID-19 cases in the general population, hospitalized patients, and patients with chronic illness. ${ }^{14,31,33,39}$ Additionally, recent studies have explored the QOL of those who have recovered from COVID-19 at home without medical intervention. ${ }^{36}$ Therefore, we aim to assess the QOL for recovered COVID-19 cases in Saudi Arabia, including non-hospitalized, hospitalized, and chronically ill patients, to understand the impact of COVID-19 on their QOL and its subscales and answer the following study objectives: identify the sociodemographic profile of recovered COVID-19 cases; assess the mean score of the overall Quality of Life Index (QLI) and its subscales among recovered COVID-19 cases; and measure significant differences of sample sociodemographic profiles, time of infection, intention for vaccination, and perception of the influence of COVID-19 on general health, history of hospitalization, and history of chronic illness in relation to QOL and its subscales. As individuals respond differently to COVID-19, the expected outcome of this study was to find a significant decline in all or some aspects of QOL based on people's sociodemographic characteristics and the impact of other factors, such as time since infection, intention for vaccination, and the perception of the influence of COVID-19 on general health, hospitalization, and chronic illness.

\section{Materials and Methods Design}

An explorative, cross-sectional, community-based study design used a self-reported electronic questionnaire, which was distributed online among survivors of COVID-19 in the Kingdom of Saudi Arabia.

\section{Sample}

Recovered COVID-19 cases were targeted according to the following inclusion criteria: those who were aged 18 or older and those with a confirmed history of COVID-19 infection. The exclusion criteria were those who were not officially confirmed to have been infected with COVID19. By the end of data collection (late May 2021), the Saudi Ministry of Health announced a cumulative 443,460 total cases and 426,589 total recoveries (data available at https://covid19.moh.gov.sa/). Based on the total number of 426,589 recovered cases, and assuming a 95\% confidence interval with a 0.5 margin of error, the calculated sample size was expected to reach 384 responses or more. 


\section{Data Collection}

Using social media (eg, WhatsApp, Twitter, and text messages), data were collected between March and May 2021 using the convenient snowball sampling technique (ie, participants were asked to refer the questionnaire link to individuals with a known history of COVID-19 infection).

\section{Instrument}

A three-part questionnaire was used. Part 1 consisted of questions about the demographic characteristics of the subjects, including their age, sex, marital status, level of education, employment status, time since diagnosis, symptoms experienced, interest in vaccination, and perception of the influence of COVID-19 on general health. Part 2 included questions about the subjects' history of chronic illness and hospitalization due to COVID-19. Part 3 was the generic version of the QLI, an instrument developed to measure individuals' QOL. ${ }^{40}$ The score includes the sum of patients' satisfaction and importance of QOL domain scores. ${ }^{41}$ The QLI was tested for psychometric properties, and it has the following four major subscales: health and functioning (HFSUB), social and economic (SOCSUB), psychological and spiritual (PSPSUB), and family (FAMSUB). ${ }^{37,42}$ The Arabic version of the generic 66item QLI questionnaire measured questions on a 6-point Likert-type scale (ie, very dissatisfied to very satisfied and very unimportant to very important). It comprised the following four subscales: HFSUB, SOCSUB, PSPSUB, and FAMSUB. The scores ranged from 0 to 30, with higher scores indicating better QOL. The instrument was tested among the Arab population with evidence of internal consistency. ${ }^{43}$ The QLI developer and the author of the Arabic translation were contacted, and approvals were obtained from both. Among people with a history of COVID-19, the study questionnaire was checked for reliability using the Cronbach's alpha test, which revealed an alpha value of 0.94 , indicating acceptable evidence of internal consistency. ${ }^{44}$ The construct validity was checked by the Spearman's product moment test (Appendix ATable S1) ${ }^{45}$ All questions measuring QOL were reliable and valid. Reliability estimates for the instrument used in this study were comparable with Halabi's findings of 0.94 and 0.97; all were above 0.80, indicating an adequate level of internal consistency. ${ }^{43,44}$ The Cronbach's alphas of all subscales were more than 0.80 , except for SOCSUB at 0.77 and FAMSUB at 0.74 , which is acceptable under Nunnally and Bernstein's criterion for adequate internal consistency ${ }^{46}$ Using the current sample, the QLI test for validity showed that all 33 items forming the four subscales were correlated, which indicates appropriate construct validity for determining the extent of the relationship between the measures that determine theoretical constructs. ${ }^{44,45}$

\section{Analysis}

Descriptive statistics for the demographic information were computed for each of the following variables: demographic characteristics; related COVID-19 questions; the HFSUB, SOCSUB, PSPSUB, and FAMSUB subscales; and the total QLI level. The categorical variables were presented as frequencies and percentages and as continuous variables as mean \pm standard deviation (SD). The subscale and QLI scores were checked for normality using the Shapiro-Wilk test, which showed a non-normal distribution. The QOL subscales and QLI scores were calculated according to the instructions of Ferrans and Powers (available at https://qli.org.uic.edu/). The means of the QOL subscales and the QLI total were compared between different sociodemographic characteristics and COVID-19-related questions using the Mann-Whitney $U$-test and the Kruskal-Wallis $H$-test. To compare the QLI and subscores of patients with respect to time since diagnosis of COVID-19, participants were divided into three groups (0-3 months, 3-6 months, and more than 6 months). The findings were presented either as the mean \pm $\mathrm{SD}$ or as a percentage of the entire group from which the categorical data were summed. The Student's $t$-test was used for normally distributed data, and the Wilcoxon ranksum test or the Kruskal-Wallis test was performed for nonnormally distributed data in the quantity distributions between patient subgroups (Appendix B- Tables S2 and S3). Statistical significance was denoted by p-value $<0.05$. All statistical analyses were carried out using SPSS software.

\section{Ethical Consideration}

This study was conducted in accordance with the Declaration of Helsinki. Ethical approval was obtained from the Institutional Review Board of the General Directorate of Health Affairs, Tabuk Region (Registration No. H-07- TU-077) and protocol \#TU-077/021/079. Participants received a full description of the purpose of the study and were informed about the researchers' commitment to research ethics. Moreover, no personal identifier was required, and only the principal investigator can 
access the data. In addition, participants were informed that data will be used and published only for research purposes. Informed consent was attached at the beginning of the online survey. Individuals who agreed to participate proceeded to the questionnaire.

\section{Results}

The study included a total of 449 post-COVID-19 cases. The mean age of participants was $36.06 \pm 11.34$ years, and the average number of days that had passed since diagnosis was 194. Most of the sample cases were female $(73.9 \%)$ and had a graduate level of education (88.2\%). Half of the cases were employed (53.5\%) and more than half were married $(64.6 \%)$. COVID-19 produced symptoms in 403 (89.8\%) of the cases. Two-thirds of the sample (66.1\%) were interested in vaccination against COVID-19. Nearly half responded that COVID-19 did not affect their general health. The majority of the sample had not been hospitalized (91.3\%) and did not have a history of chronic illness (83.5\%) (Table 1).

The mean QLI subscale scores were as follows: HFSUB (21.86 \pm 5.03), SOCSUB (20.86 \pm 5.04$)$, PSPSUB $(24.99 \pm 4.74)$, and FAMSUB $(24.20 \pm 4.87)$. The mean total QLI score was $22.64 \pm 4.36$ (Table 2).

When assessing the correlation between age, time since diagnosis, and QLI subscales, we found there was no significant correlation between age and the subscales, except for with FAMSUB $(\mathrm{p}=0.04)$; time since diagnosis and subscales and total QLI score was observed $(\mathrm{p}>$ 0.050 ). However, the subscales were significantly positively correlated with each other and with the total QLI score (all p-values $=0.000)$ (Table 3 ).

By examining the relationship between sample sociodemographic characteristics and QOL subscales, we found that males $(22.74 \pm 5.33)$ had significantly higher HFSUB scores than females $21.59 \pm 4.90(\mathrm{p}=0.033)$. Employed cases $(21.55 \pm 5.33)$ had significantly higher SOCSUB scores than unemployed cases $(19.59 \pm 5.14 ; \mathrm{p}=0.000)$. The QLI total was similar for all cases across sociodemographic characteristics. Those whose general health was affected by COVID-19 had significantly lower HFSUB scores $(p=0.000)$ and PSPSUB scores $(p=0.021)$. A comparison of QOL subscales for individuals with a history of chronic infections against those who had no chronic infection showed that SOCSUB and PSPSUB scores were higher for the former (Table 4). However, individuals with a history of hospital admissions had
Table I Socio-Demographic Characteristics of All Cases and Responses to Covid-19 Related Questions $(n=449)$

\begin{tabular}{|c|c|}
\hline Characteristics & $\mathbf{N}(\%)$ \\
\hline Age in years (Mean $\pm S D$ ) & $36.06 \pm 11.34$ \\
\hline Time since diagnosis (days) & $194.37 \pm 86.64$ \\
\hline \multicolumn{2}{|l|}{ Gender } \\
\hline Male & $117(26.1)$ \\
\hline Female & $332(73.9)$ \\
\hline \multicolumn{2}{|l|}{ Education level } \\
\hline Primary & $\mathrm{I}(0.2)$ \\
\hline Intermediate & $4(0.9)$ \\
\hline High school & $52(12)$ \\
\hline Diploma & $8(1.8)$ \\
\hline Graduate & $368(82.0)$ \\
\hline Master's Degree & II (2.4) \\
\hline Doctoral degree & $2(0.4)$ \\
\hline \multicolumn{2}{|l|}{ Employment status } \\
\hline Student & $77(17.1)$ \\
\hline Employed & $240(53.5)$ \\
\hline Not employed & $132(29.4)$ \\
\hline \multicolumn{2}{|l|}{ Marital status } \\
\hline Single & $140(3 \mid .2)$ \\
\hline Married & $290(64.5)$ \\
\hline Divorced & $13(2.9)$ \\
\hline Widowed & $6(1.3)$ \\
\hline \multicolumn{2}{|l|}{ Symptoms of COVID-19 } \\
\hline Yes & $403(89.8)$ \\
\hline No & $46(10.2)$ \\
\hline \multicolumn{2}{|l|}{ Interested in vaccination against COVID-19 } \\
\hline Yes & $297(66.1)$ \\
\hline No & $152(33.9)$ \\
\hline \multicolumn{2}{|l|}{ Effect of COVID-19 on general health } \\
\hline Yes & $124(27.6)$ \\
\hline Maybe & $127(28.3)$ \\
\hline No & $198(44.1)$ \\
\hline \multicolumn{2}{|l|}{ History of hospitalization } \\
\hline Yes & $39(8.7)$ \\
\hline No & $410(91.3)$ \\
\hline \multicolumn{2}{|l|}{ History of chronic illness } \\
\hline Yes & $74(16.5)$ \\
\hline No & $375(83.5)$ \\
\hline
\end{tabular}

Abbreviation: SD, standard deviation.

lower SOCSUB and PSPSUB scores than individuals who had not (Table 4).

In comparison of mean QLI and other subscales with respect to time since diagnosis of COVID-19, the SOCSUB 
Table 2 The Mean Subscales and Total Quality of Life Scores ( $n=449)$

\begin{tabular}{|l|l|l|}
\hline Scales & Mean & SD \\
\hline Health and functioning subscale score & 21.86 & 5.03 \\
Social and economic subscale score & 20.86 & 5.04 \\
Psychological/spiritual subscale score & 24.99 & 4.74 \\
Family subscale score & 24.20 & 4.87 \\
Total score (QLI) & 22.64 & 4.36 \\
\hline
\end{tabular}

Abbreviations: SD, standard deviation; OLI, Quality of Life Index.

scores gradually increased in patients who had been diagnosed with COVID-19 0-3 months before (19.80 \pm 5.21$), 3-$ 6 months $(21.08 \pm 5.21)$, and more than 6 months $(21.11 \pm$ 4.87). Similarly, FAMSUB scores were lower in patients at $0-3$ months $(23.90 \pm 5.13)$ than in patients who had been diagnosed 3-6 months before $(24.55 \pm 4.74)$ and more than 6 months $(24.11 \pm 4.88)$. Figure 1 represents the clustered bar mean of QLI and other subscales with respect to time in months after COVID-19 diagnosis.

A comparison of the QOL subscales for individuals with a history of chronic infections and those with no chronic infections showed no significant difference (Table 4). Figure 2 represents the clustered bar mean of QLI and other subscales for patients with and without chronic illness. Similarly, patients who had been admitted to the hospital for COVID-19 reported lower PSPSUB scores (25.00 \pm 4.74) than those who had not $(30.00 \pm 0.00)$. The remaining subscale scores and QLI were more or less similar in patients with or without hospital admissions. Figure 3 represents the clustered bar mean of QLI and other subscales for patients with and without hospital admissions.

\section{Discussion}

This study assessed the QOL of people who have recovered from COVID-19 using the QLI and exploring significant correlations with sample sociodemographic characteristics. As the instrument was valid, it was expected to demonstrate a strong association between the total QLI score and its subscales and between the subscales. These associations were consistent with other QOL studies, although a different tool was used. ${ }^{14}$ In the current study, the SOCSUB mean score was the least comparable to the other subscales. Indeed, COVID-19 patients faced quarantine for 10-14 days with zero social interaction, so the prevalence of loneliness was high among those who experienced COVID-19-related symptoms. ${ }^{47}$ Despite the benefits of social distancing and quarantine, there were consequences on individuals' social well-being. ${ }^{8,48}$ Therefore, Saudi Arabia faces economic and social challenges as a consequence of government measures to reduce the spread of COVID-19 infection. ${ }^{49}$

When examining the relationship between the total QLI score and its subscales with the sample sociodemographic attributes, age showed a significant correlation with FAMSUB. This association can be explained by familial bonding and support in Saudi culture, especially for sick people. ${ }^{50}$ Both young and older adults were at risk of loneliness and its consequences for their wellbeing. ${ }^{51,52}$ Lower levels of general health, physical function, and spiritual well-being were also associated with older age. ${ }^{33,53}$ The time since diagnosis had no correlation with the QLI score or its subscales. This finding was similar to that of Garratt et al, who found that QOL has overall good scores except for mental well-being. ${ }^{36}$

Gender was associated with HFSUB, as males reported higher scores than females, which contradicts other studies reporting that males face more deterioration and complications than females. ${ }^{54}$ The sample had a majority of female participants; however, males have been found to be more susceptible to COVID-19 infection. ${ }^{55}$ Many studies have

Table 3 Correlation Between Age, Time Elapsed from Diagnosis, Subscale Scores and Total Quality of Life Index ( $\mathrm{n=449)}$

\begin{tabular}{|l|l|l|l|l|l|l|l|}
\hline & Age & $\begin{array}{l}\text { Time Elapsed from } \\
\text { Diagnosis }\end{array}$ & $\begin{array}{l}\text { HFSUB } \\
\text { Score }\end{array}$ & $\begin{array}{l}\text { SOCSUB } \\
\text { Score }\end{array}$ & $\begin{array}{l}\text { PSPSUB } \\
\text { Score }\end{array}$ & $\begin{array}{l}\text { FAMSUB } \\
\text { Score }\end{array}$ & $\begin{array}{l}\text { Total QLI } \\
\text { Score }\end{array}$ \\
\hline Age & 1.000 & 0.066 & -0.025 & $0.130 *$ & 0.079 & 0.097 & 0.059 \\
Time elapsed from diagnosis & & 1.000 & 0.021 & 0.019 & 0.028 & 0.019 & 0.025 \\
HFSUB score & & & 1.000 & $0.692 * *$ & $0.772 * *$ & $0.707 * *$ & $0.945 * *$ \\
SOCSUB score & & & 1.000 & $0.700^{* *}$ & $0.534^{* *}$ & $0.845^{* *}$ \\
PSPSUB score & & & & 1.000 & $0.613^{* *}$ & $0.880^{* *}$ \\
FAMSUB score & & & & & 1.000 & $0.780^{* *}$ \\
\hline
\end{tabular}

Notes: test used=Spearman correlation coefficient $(r)$. *P $<0.05$, **P $<0.00$.

Abbreviations: HFSUB, health and functioning subscale; SOCSUB, social and economic subscale; PSPSUB, psychological and spiritual subscale; FAMSUB, family subscale; OLI, Quality of Life Index. 


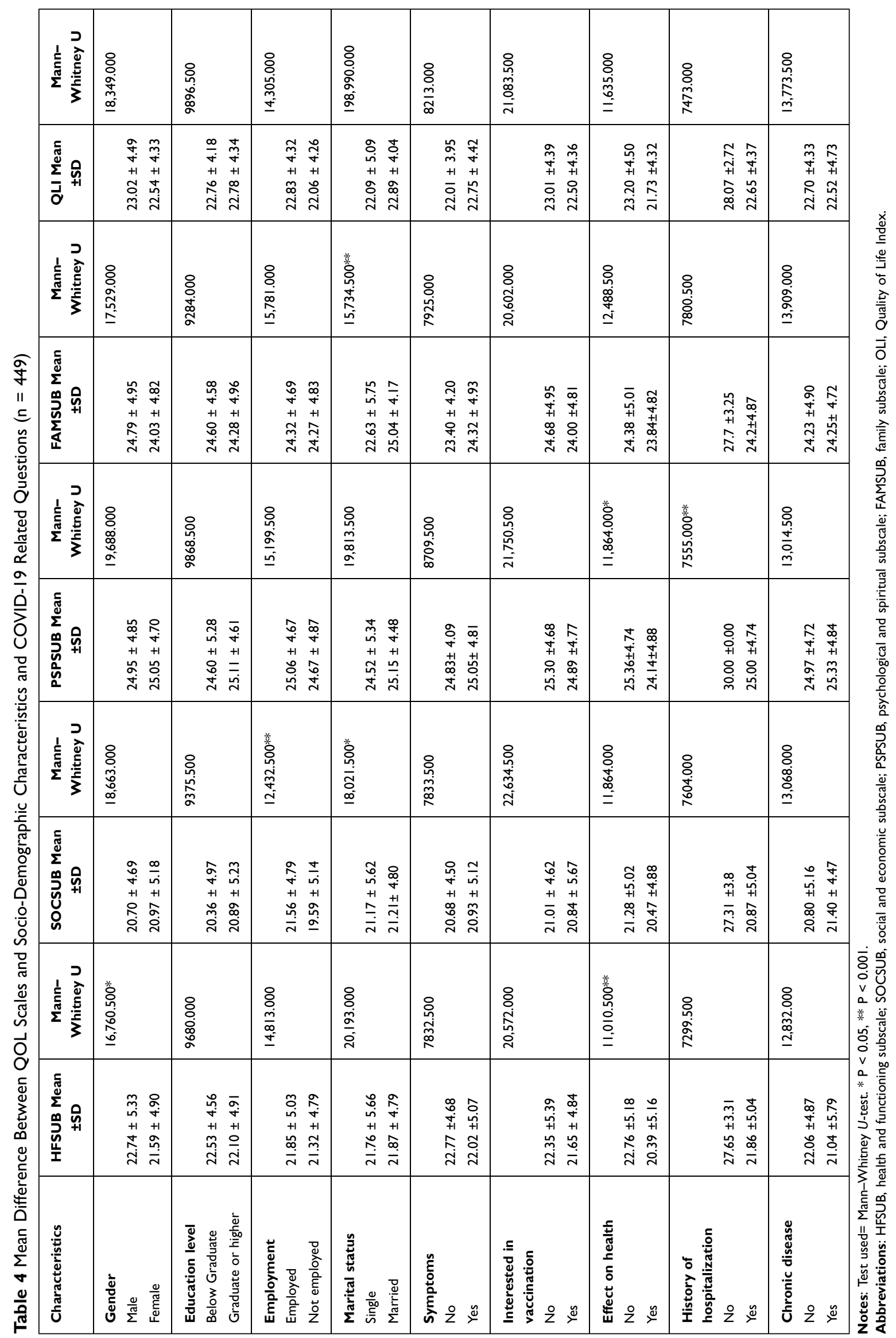




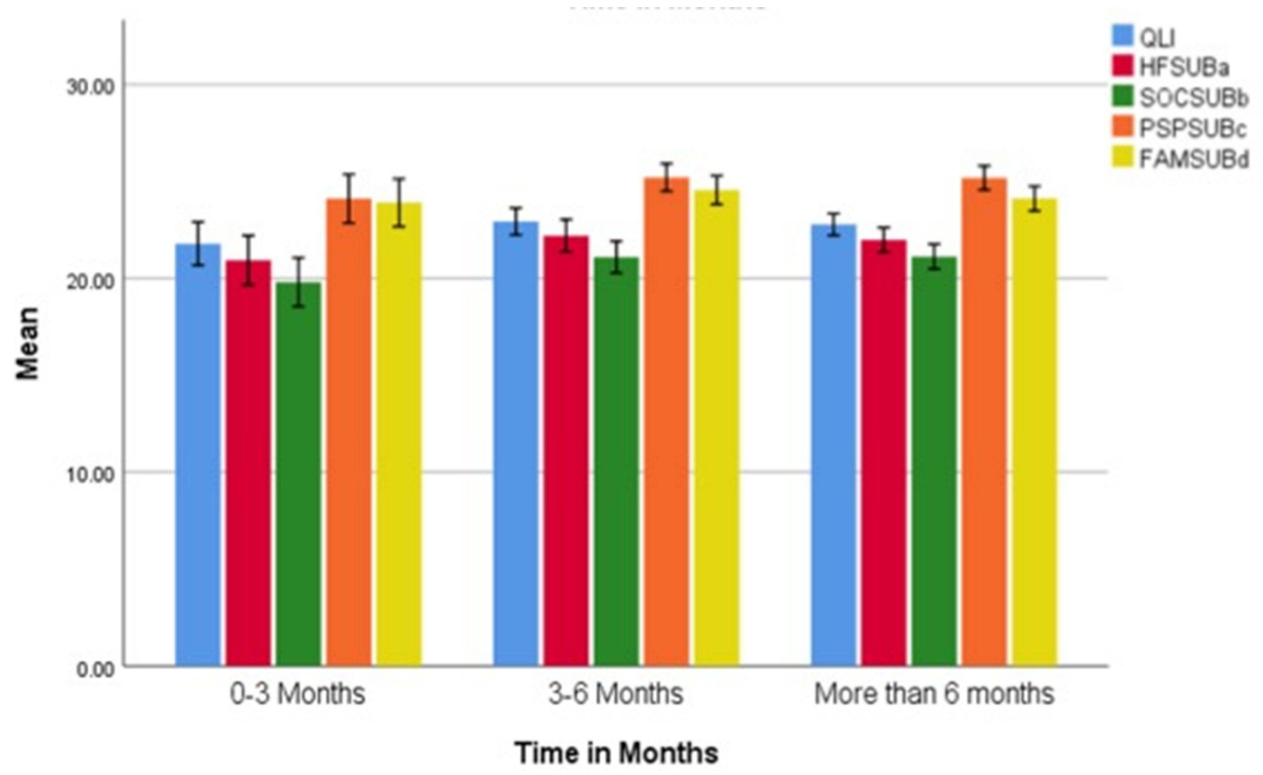

Figure I Clustered bar mean of QLI and other subscales with respect to time in months after COVID-19 diagnosis.

Abbreviations: HFSUBa, health and functioning subscale; SOCSUBb, social and economic subscale; PSPSUBc, psychological and spiritual subscale; FAMSUBd, family subscale; OLI, Quality of Life Index.

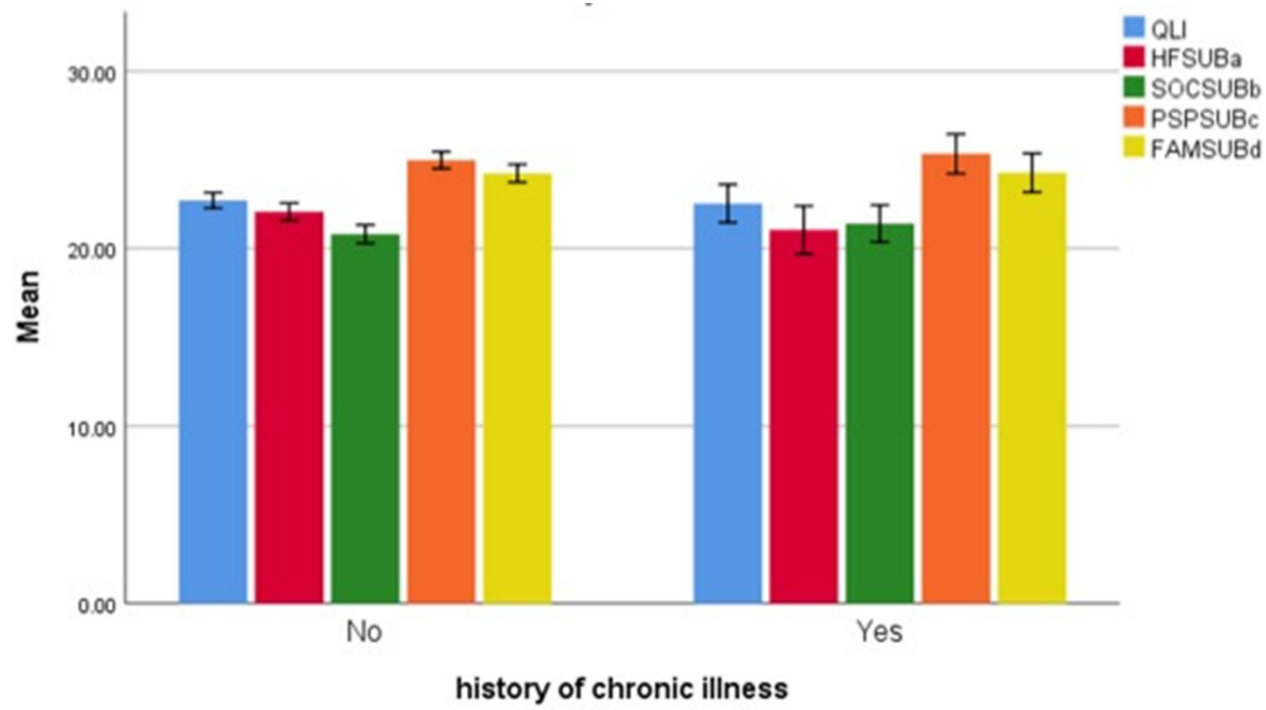

Figure 2 Clustered bar mean of QLI and other subscales according to history of chronic illness.

Abbreviations: HFSUBa, health and functioning subscale; SOCSUBb, social and economic subscale; PSPSUBc, psychological and spiritual subscale; FAMSUBd, family subscale; OLI, Quality of Life Index.

shown that males also have higher levels of disease severity and fatality than females. ${ }^{54,56}$ Employment status had a significant relationship with SOCSUB. Indeed, there has been a massive effect of COVID-19 on the global economy that has influenced individuals' socioeconomic position. ${ }^{30}$ Many people have lost their jobs during the pandemic, leading to a reduction in economic activities. ${ }^{57}$ Therefore, the influence of COVID-19 on employment has been universal, not only in Saudi Arabia. Married participants reported higher FAMSUB scores than single participants. Although many studies have shown that COVID-19 may have negative influences on couples' relationships, ${ }^{58,59}$ Saudi culture is characterized by strong relationships among families, especially those with a sick spouse. ${ }^{50}$ 


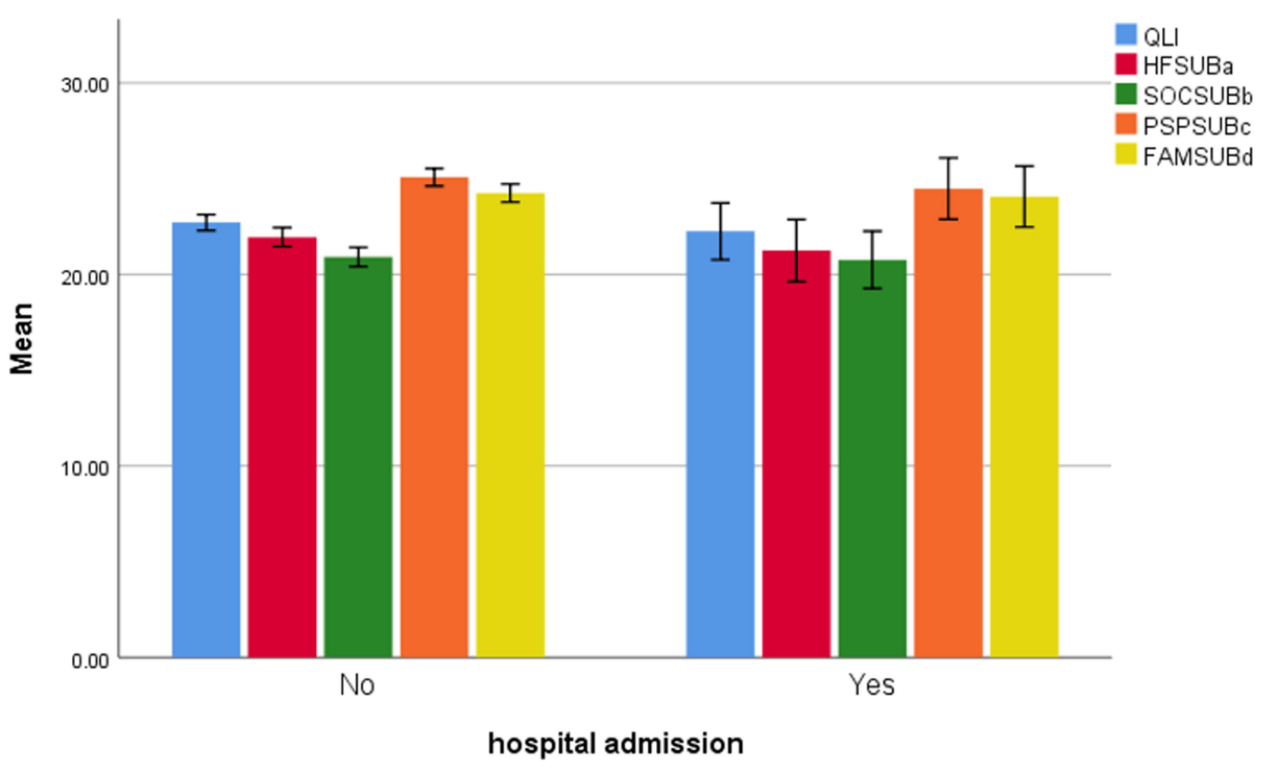

Figure 3 Clustered bar mean of QLI and other subscales according to history of hospital admission.

Abbreviations: HFSUBa, health and functioning subscale; SOCSUBb, social and economic subscale; PSPSUBc, psychological and spiritual subscale; FAMSUBd, family subscale; OLI, Quality of Life Index.

Participants' perceptions of the impact of COVID-19 on their health had significant associations with HFSUB and PSPSUB. This means that participants could interpret their own perceptions of their QOL; one-half mentioned that it had or might have an effect on their health. Many studies have supported this by reporting that COVID-19 patients have experienced a decline in physical, psychological, and spiritual health. ${ }^{9,16,25,31}$

When comparing groups, SOCSUB and FAMSUB scores gradually increased with time. However, based on previous studies, COVID-19 patients cannot return to their normal lives within 1-6 months of hospital discharge, especially those with chronic illness. $^{25,26,33}$ Our findings showed that PSPSUB was lower among those who had been hospitalized. One study reported that the prevalence of depression was associated with hospitalized patients. ${ }^{9}$ In addition, psychological impairment was found one month after hospital discharge. ${ }^{31}$ Symptoms experienced, participants' interest in vaccination, and chronic illness had no significant association with the total QLI score or any of its subscales. Overall QOL among the studied sample was 22.6 compared with the maximum score of the instrument of 30. Other studies have shown a greater decline in QOL after COVID-19 infection, especially in the physical and psychological well-being of hospitalized patients. ${ }^{9,31,33}$ In contrast, one contradicting study reported a good QOL of non-hospitalized COVID-19 patients. $^{36}$
This study has some limitations. The concept of QOL is still being questioned, largely because it is based on peoples' preferences. While perspectives of QOL may differ on an individual basis, the measures and instrumentscoring requirements in this study constrained peoples' choices. ${ }^{38}$ The results cannot be generalized for the following reasons. The sample size might not be representative, and the online questionnaire was self-reported. Response bias could be expected (ie, when participants answer to please the researcher). Furthermore, the crosssectional nature of the study and time limitations in data collection (ie, two months) could not account for the longterm effects of COVID-19 on patients' QOL. The lack of a baseline measure did not allow for comparing QOL after COVID-19 infection. The variation of time since diagnosis could be a confounder. The assessment of mental health was not applicable for this study, as mental well-being was not part of the QLI.

Many areas of COVID-19-related issues have not yet been explored. This invites researchers to explore moredetailed QOL findings in relation to COVID-19, especially for non-hospitalized patients, who account for the majority of infected cases. Follow-up studies with a wide range of sample characteristics are recommended to allow for comparison. Further physical and psychological evaluations would be beneficial for both hospitalized and non-hospitalized patients 
who have contracted COVID-19 infection in order to plan future interventions to help them recover from the pandemic.

\section{Conclusion}

For use in people with a history of COVID-19, the Arabic version of generic QLI was valid and reliable. COVID-19 has altered many aspects of people's QOL. Sociodemographic characteristics of individuals with a history of COVID-19 revealed significant differences in some domains of QOL, as measured by the Arabic version of the generic QLI. People's beliefs about the impact of COVID-19 on general health and history of hospitalization were mainly influenced by their health, functioning, psychological, and spiritual well-being.

\section{Disclosure}

The author declares no conflicts of interest in this work.

\section{References}

1. Huang Y, Zeng G, Chen G, et al. Clinical Features of Middle-Aged Patients Died of 2019 Novel Coronavirus-Infected Pneumonia. Research Square; 2020.

2. WHO. Naming the Coronavirus Disease (COVID-19) and the Virus That Causes It; 2020.

3. Armocida B, Formenti B, Ussai S, Palestra F, Missoni E. The Italian health system and the COVID-19 challenge. Lancet Public Health 2020;5(5):e253. doi:10.1016/S2468-2667(20)30074-8

4. Quigley AL, Stone H, Nguyen PY, Chughtai AA, MacIntyre CR. Estimating the burden of COVID-19 on the Australian healthcare workers and health system during the first six months of the pandemic. Int $J$ Nurs Stud. 2021;114:103811. doi:10.1016/j. ijnurstu.2020.103811

5. Kramer V, Papazova I, Thoma A, et al. Subjective burden and perspectives of German healthcare workers during the COVID-19 pandemic. Eur Arch Psychiatry Clin Neurosci. 2021;271(2):271-281. doi:10.1007/s00406-020-01183-2

6. Miller IF, Becker AD, Grenfell BT, Metcalf CJE. Disease and healthcare burden of COVID-19 in the United States. Nat Med. 2020;26 (8):1212-1217. doi:10.1038/s41591-020-0952-y

7. Alshammari TM, Altebainawi AF, Alenzi KA. Importance of early precautionary actions in avoiding the spread of COVID-19: Saudi Arabia as an example. Saudi Pharm J. 2020;28(7):898-902. doi:10.1016/j.jsps.2020.05.005

8. Alrashed S, Min-Allah N, Saxena A, Ali I, Mehmood R. Impact of lockdowns on the spread of COVID-19 in Saudi Arabia. Inform Med Unlocked. 2020;20:100420. doi:10.1016/j.imu.2020.100420

9. Ma YF, Li W, Deng HB, et al. Prevalence of depression and its association with quality of life in clinically stable patients with COVID-19. J Affect Disord. 2020;275:145-148. doi:10.1016/j. jad.2020.06.033

10. Zhang Y, Ma ZF. Impact of the COVID-19 pandemic on mental health and quality of life among local residents in Liaoning Province, China: a Cross-Sectional Study. Int J Environ Res Public Health. 2020;17(7):2381. doi:10.3390/ijerph17072381

11. Qi M, Li P, Moyle W, Weeks B, Jones C. Physical activity, health-related quality of life, and stress among the Chinese adult population during the COVID-19 pandemic. Int $J$ Environ Res Public Health. 2020;17(18):6494. doi:10.3390/ijerph17186494
12. Ivbijaro G, Brooks C, Kolkiewicz L, Sunkel C, Long A. Psychological impact and psychosocial consequences of the COVID 19 pandemic resilience, mental well-being, and the coronavirus pandemic. Indian J Psychiatry. 2020;62(Suppl 3):S395-S403. doi:10.4103/psychiatry.IndianJPsychiatry_1031_20

13. Alhachem E, Haddad G, Nagib E, Ikdais W, Akkari M. Anxiety in Lebanon during the COVID-19 pandemic. Arab J Psychiatry. 2020;31(2):105-119. 15.

14. Algahtani FD, Hassan SU, Alsaif B, Zrieq R. Assessment of the quality of life during COVID-19 pandemic: a cross-sectional survey from the Kingdom of Saudi Arabia. Int J Environ Res Public Health. 2021;18(3):847. doi:10.3390/ijerph18030847

15. Epifanio MS, Andrei F, Mancini G, et al. The impact of COVID-19 pandemic and lockdown measures on quality of life among Italian general population. $J$ Clin Med. 2021;10(2):289. doi:10.3390/ jem10020289

16. Coppola I, Rania N, Parisi R, Lagomarsino F. Spiritual well-being and mental health during the COVID-19 pandemic in Italy. Front Psychiatry. 2021;12:626944. doi:10.3389/fpsyt.2021.626944

17. Hay JW, Gong CL, Jiao X, et al. A US population health survey on the impact of COVID-19 using the EQ-5D-5L. J Gen Intern Med. 2021;36(5):1292-1301. doi:10.1007/s11606-021-06674-z

18. Azizi A, Achak D, Aboudi K, et al. Health-related quality of life and behavior-related lifestyle changes due to the COVID-19 home confinement: dataset from a Moroccan sample. Data Brief. 2020;32:106239. doi:10.1016/j.dib.2020.106239

19. Ungureanu BS, Vladut C, Bende F, et al. Impact of the COVID-19 pandemic on health-related quality of life, anxiety, and training among young gastroenterologists in Romania. Front Psychol. 2020;11:579177. doi:10.3389/fpsyg.2020.579177

20. Turcu-Stiolica A, Bogdan M, Subtirelu M-S, et al. Influence of COVID-19 on health-related quality of life and the perception of being vaccinated to prevent COVID-19: an approach for community pharmacists from Romania and Bulgaria. J Clin Med. 2021;10 (4):864. doi: $10.3390 / \mathrm{jcm} 10040864$

21. Buttery S, Philip K, Williams P, et al. Patient symptoms and experience following COVID-19: results from a UK wide survey. Available at SSRN 3834303; 2021.

22. Fernandez-de-las-penas C, Palacios-Cena D, Gomez-Mayordomo V, Cuadrado ML, Florencio LL. Defining post-COVID symptoms (Post-acute COVID, long COVID, persistent post-COVID): an integrative classification. Int J Environ Res Public Health. 2021;18 (5):2621. doi:10.3390/ijerph18052621

23. Al-Aly Z, Xie Y, Bowe B. High-dimensional characterization of post-acute sequelae of COVID-19. Nature. 2021;594 (7862):259-264. doi:10.1038/s41586-021-03553-9

24. Davis HE, Assaf GS, McCorkell L, et al. Characterizing long COVID in an international cohort: 7 months of symptoms and their impact. EClinicalMedicine. 2021;38:101019. doi:10.1016/j.eclinm.2021.101019

25. Stavem K, Ghanima W, Olsen MK, Gilboe HM, Einvik G. Persistent symptoms 1.5-6 months after COVID-19 in non-hospitalised subjects: a population-based cohort study. Thorax. 2021;76(4):405-407. doi:10.1136/thoraxjn1-2020-216377

26. Dennis A, Wamil M, Alberts J, et al. Multiorgan impairment in low-risk individuals with post-COVID-19 syndrome: a prospective, community-based study. BMJ Open. 2021;11(3):e048391. doi:10.1136/bmjopen-2020-048391

27. Lebow JL. Family in the age of COVID-19. Fam Process. 2020;59 (2):309-312. doi:10.1111/famp.12543

28. Prime $\mathrm{H}$, Wade $\mathrm{M}$, Browne DT. Risk and resilience in family well-being during the COVID-19 pandemic. Am Psychol. 2020;75 (5):631-643. doi:10.1037/amp0000660

29. Tandon PN. COVID-19: impact on health of people \& wealth of nations. Indian J Med Res. 2020;151(2 \& 3):121-123. doi:10.4103/ ijmr.IJMR_664_20 
30. Nicola M, Alsafi Z, Sohrabi C, et al. The socio-economic implications of the coronavirus pandemic (COVID-19): a review. Int J Surg. 2020;78:185-193. doi:10.1016/j.ijsu.2020.04.018

31. Chen K-Y, Li T, Gong F, Zhang J-S, Li X-K. Predictors of health-related quality of life and influencing factors for COVID-19 patients, a follow-up at one month. Front Psychiatry. 2020;11:668. doi:10.3389/fpsyt.2020.00668

32. Jacobs LG, Gourna Paleoudis E, Lesky-Di Bari D, et al. Persistence of symptoms and quality of life at 35 days after hospitalization for COVID-19 infection. PLoS One. 2020;15(12):e0243882. doi:10.1371/journal.pone.0243882

33. Qu G, Zhen Q, Wang W, et al. Health-related quality of life of COVID-19 patients after discharge: a multicenter follow-up study. J Clin Nurs. 2021;30(11-12):1742-1750. doi:10.1111/jocn.15733

34. Vaes AW, Machado FVC, Meys R, et al. Care dependency in non-hospitalized patients with COVID-19. J Clin Med. 2020;9 (9):2946. doi:10.3390/jcm9092946

35. Mehraeen E, Hayati B, Saeidi S, Heydari M, Seyedalinaghi S. Selfcare instructions for people not requiring hospitalization for Coronavirus Disease 2019 (COVID-19). Arch Clin Infect Dis. 2020;15(COVID-19):e102978. doi:10.5812/archcid.102978

36. Garratt AM, Ghanima W, Einvik G, Stavem K. Quality of life after COVID-19 without hospitalisation: good overall, but reduced in some dimensions. $J$ Infect. 2021;82(5):186-230. doi:10.1016/j. jinf.2021.01.002

37. Ferrans CE. Development of a quality of life index for patients with cancer. Oncol Nurs Forum. 1990;17(3 Suppl):15-19; discussion 20-11.

38. Carr AJ, Higginson IJ. Are quality of life measures patient centred? BMJ. 2001;322(7298):1357-1360. doi:10.1136/bmj.322.7298.1357

39. Wu C, Cheng J, Zou J, Duan L, Campbell JE. Health-related quality of life of hospitalized COVID-19 survivors: an initial exploration in Nanning city, China. Soc Sci Med. 2021;274:113748. doi:10.1016/j. socscimed.2021.113748

40. Ferrans CE, Powers MJ. Quality of Life Index: QLI. College of Nursing, University of Illinois at Chicago; 1984.

41. Ferrans CE. Development of a conceptual model of quality of life. Sch Inq Nurs Pract. 1996;10(3):293-304.

42. Ferrans CE, Powers MJ. Psychometric assessment of the quality of life index. Res Nurs Health. 1992;15(1):29-38. doi:10.1002/ nur.4770150106

43. Halabi JO. Psychometric properties of the Arabic version of quality of life index. J Adv Nurs. 2006;55(5):604-610. doi:10.1111/j.13652648.2006.03952 1.x

44. Carmines EG, Ze-ller RA. Reliability and Validity Assessment. Sage publications; 1979.

45. Karras DJ. Statistical methodology: II. Reliability and variability assessment in study design, Part A. Acad Emerg Med. 1997;4 (1):64-71. doi:10.1111/j.1553-2712.1997.tb03646.x

46. Nunnally J, Bernstein I. Psychometric Theory. McGraw-Hill Companies, Incorporated; 1994.
47. Li LZ, Wang S. Prevalence and predictors of general psychiatric disorders and loneliness during COVID-19 in the United Kingdom. Psychiatry Res. 2020;291:113267. doi:10.1016/j.psychres.20 20.113267

48. Saladino V, Algeri D, Auriemma V. The psychological and social impact of Covid-19: new perspectives of well-being. Front Psychol. 2020;11(2550):577684. doi:10.3389/fpsyg.2020.577684

49. Yezli S, Khan A. COVID-19 social distancing in the Kingdom of Saudi Arabia: bold measures in the face of political, economic, social and religious challenges. Travel Med Infect Dis. 2020;37:101692. doi:10.1016/j.tmaid.2020.101692

50. Alrubaishi D, McAdam M, Harrison R. Culture, Islamic capital and the entrepreneurial behaviour of family firms in Saudi Arabia. Int J Entrep Behav Res. 2021;27(6):1476-1501. doi:10.1108/IJEBR09-2020-0575

51. Groarke JM, Berry E, Graham-Wisener L, McKenna-Plumley PE, McGlinchey E, Armour C. Loneliness in the UK during the COVID-19 pandemic: cross-sectional results from the COVID-19 Psychological Wellbeing Study. PLoS One. 2020;15(9):e0239698. doi:10.1371/journal.pone. 0239698

52. Savage RD, Wu W, Li J, et al. Loneliness among older adults in the community during COVID-19: a cross-sectional survey in Canada. BMJ Open. 2021;11(4):e044517. doi:10.1136/bmjopen-2020-044517

53. Rababa M, Hayajneh AA, Bani-Iss W. Association of death anxiety with spiritual well-being and religious coping in older adults during the COVID-19 pandemic. $J$ Relig Health. 2021;60(1):50-63. doi:10.1007/s10943-020-01129-x

54. Qian J, Zhao L, Ye RZ, Li XJ, Liu YL. Age-dependent gender differences in COVID-19 in Mainland China: Comparative Study. Clin Infect Dis. 2020;71(9):2488-2494. doi:10.1093/cid/ciaa683

55. Foresta C, Rocca MS, Di Nisio A. Gender susceptibility to COVID-19: a review of the putative role of sex hormones and $\mathrm{X}$ chromosome. J Endocrinol Invest. 2021;44(5):951-956. doi:10.1007/ s40618-020-01383-6

56. Mukherjee S, Pahan K. Is COVID-19 gender-sensitive? J Neuroimmune Pharmacol. 2021;16(1):38-47. doi:10.1007/s11481020-09974-Z

57. Cho SJ, Lee JY, Winters JV. Employment impacts of the COVID-19 pandemic across metropolitan status and size; 2020.

58. Pietromonaco PR, Overall NC. Applying relationship science to evaluate how the COVID-19 pandemic may impact couples' relationships. Am Psychol. 2021;76(3):438-450.

59. Arafat SMY, Alradie-Mohamed A, Kar SK, Sharma P, Kabir R. Does COVID-19 pandemic affect sexual behaviour? A cross-sectional, cross-national online survey. Psychiatry Res. 2020;289:113050. doi:10.1016/j.psychres.2020.113050
Patient Preference and Adherence

\section{Publish your work in this journal}

Patient Preference and Adherence is an international, peer-reviewed, open access journal that focusing on the growing importance of patient preference and adherence throughout the therapeutic continuum. Patient satisfaction, acceptability, quality of life, compliance, persistence and their role in developing new therapeutic modalities and compounds to optimize clinical outcomes for existing disease states are major areas of interest for the journal. This journal has been accepted for indexing on PubMed Central. The manuscript management system is completely online and includes a very quick and fair peer-review system, which is all easy to use. Visit http:// www.dovepress.com/testimonials.php to read real quotes from published authors. 